\title{
Intraoperative SpyGlass to determine extension of pancreatic resection in main duct intraductal papillary mucinous neoplasm associated with pancreas divisum
}

The International Association of Pancreatology recommends that main duct intraductal papillary mucinous neoplasm (IPMN) be treated with partial pancreatectomy [1] if surgical margins are negative for high-grade dysplasia (HGD) and invasive carcinoma, avoiding total pancreatectomy [2]. However, it is difficult to determine the exact margins of resection during duodenopancreatectomy for main duct IPMN. The latest guidelines recommend SpyGlass to obtain precise measures of margin extension before surgery [1].

The patient was an asymptomatic 63 -year-old man. Routine ultrasound showed main duct dilatation $(6 \mathrm{~mm})$, and magnetic resonance imaging (MRI) showed pancreas divisum with signs of chronic pancreatitis. The patient's main duct dilatation evolved from $6 \mathrm{~mm}$ to $32 \mathrm{~mm}$ at 2 years of follow-up ( Fig. 1 ). Imaging exams confirmed the diagnosis of IPMN, and duodenopancreatectomy was proposed. The MRI left doubt about the resection margin, and SpyGlass was indicated. A bulging papilla with mucoid secretion was observed (>Fig.2), and pancreatic sphincterotomy was performed to improve SpyGlass access ( Fig.3). Tissue fragments were obtained and revealed HGD at the pancreatic tail ( $\mathbf{F i g . 4 ) . ~ T o t a l ~ p a n c r e a t e c t o m y ~ w a s ~}$ uneventful and the patient was discharged after 7 days with blood glucose levels stabilized by insulin ( $>$ Video 1 ). The biopsies revealed the presence of HGD, and it was not necessary to perform the section of the margins to be frozen during surgery. However, one limitation of SpyGlass is the diameter of the main duct, which needs to be dilated (>5 mm) once the diameter of the Spyscope is $3.46 \mathrm{~mm}$ [2]. In this case, be-

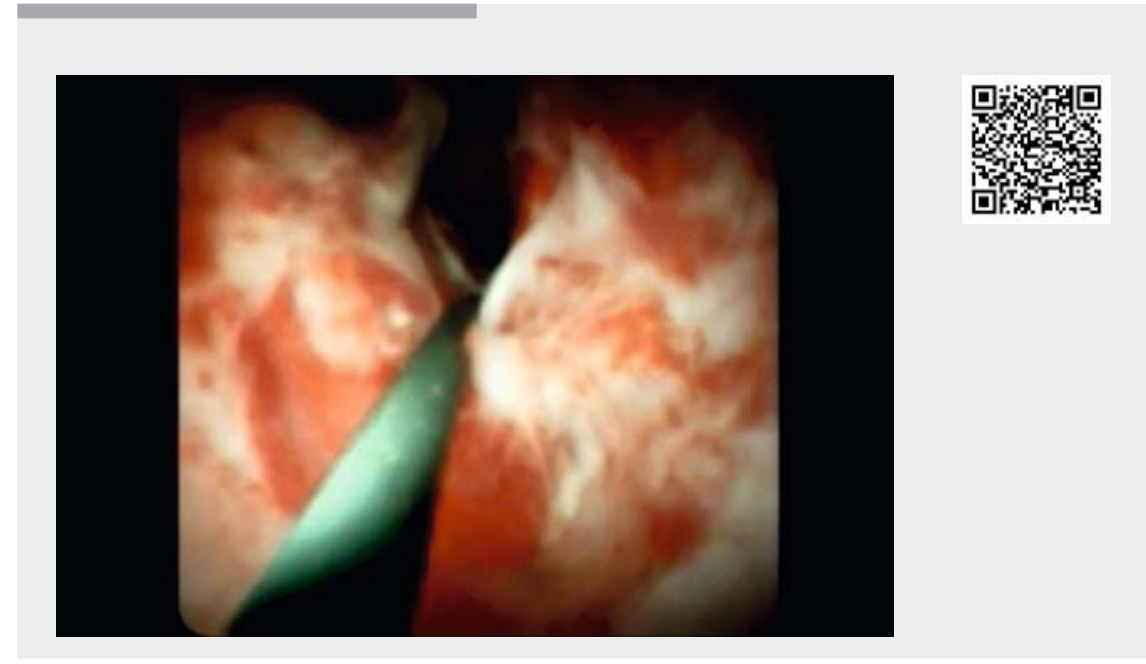

$\checkmark$ Video 1 SpyGlass was used intraoperatively to determine extension of pancreatic resection in main duct intraductal papillary mucinous neoplasm associated with pancreas divisum. Total pancreatectomy was ultimately performed and patient course was uneventful.
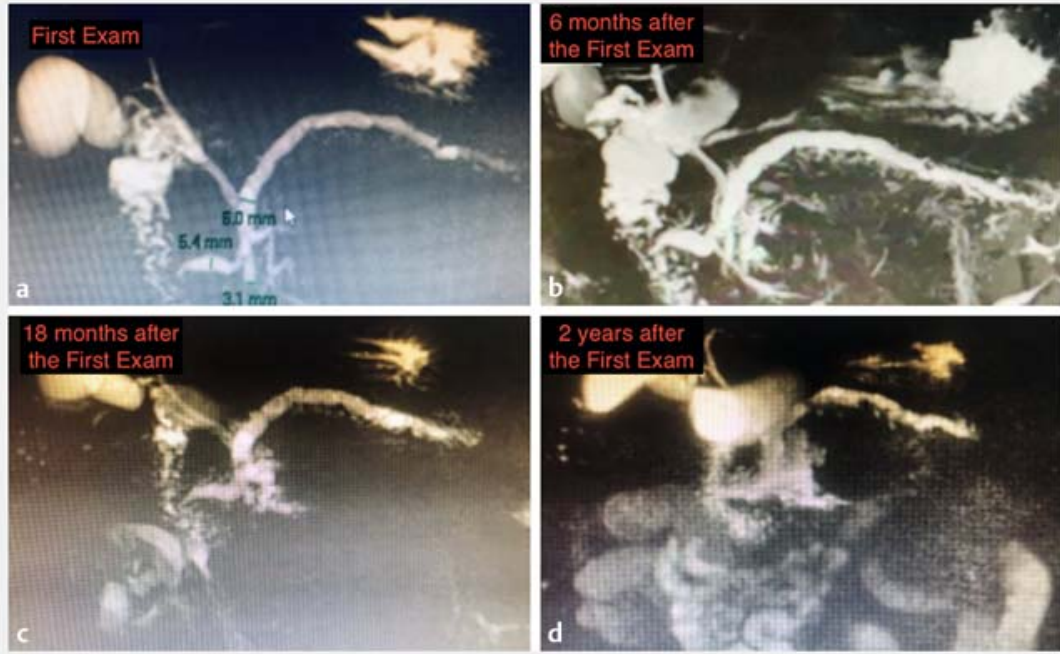

Fig. 1 Seriated images of magnetic resonance cholangiopancreatography (MRCP). Note the diffuse enlargement of the main pancreatic duct, particularly enhanced at the pancreatic head. Dorsal main pancreatic duct drains to the minor duodenal papilla. a, b, c MRCP revealed chronic pancreatitis associated with pancreas divisum. $\mathbf{d}$ The image suggested a main duct intraductal papillary mucinous neoplasm located at the pancreatic head. 

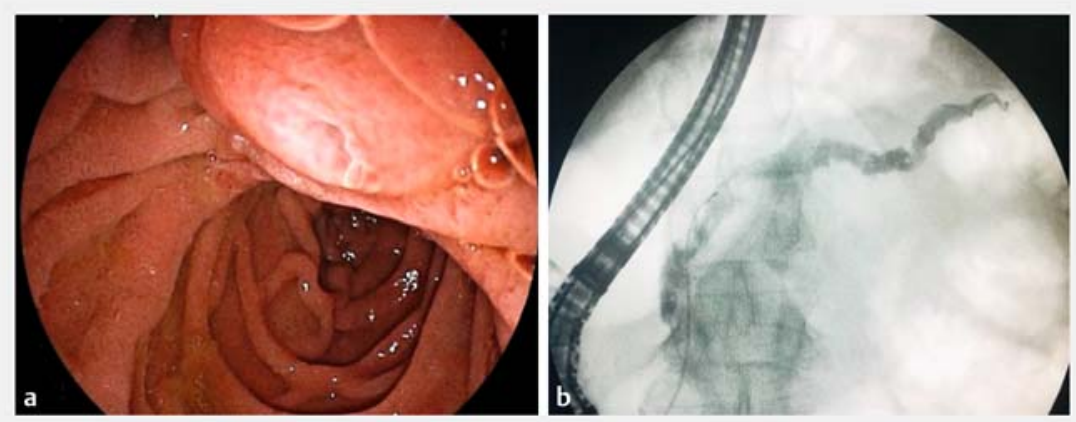

Fig. 2 a Endoscopic image of the duodenal papilla with eruption of mucoid secretion. b Pancreatography revealing defective filling of the pancreatic head and main pancreatic duct tortuosity with guidewire positioned on the pancreatic tail.
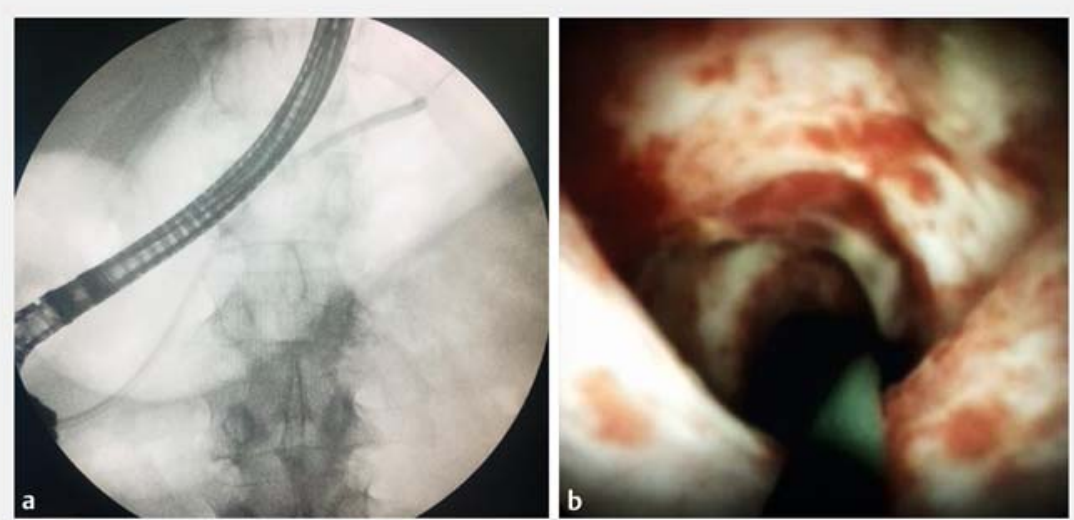

- Fig. 3 a Fluoroscopy image of SpyGlass positioned on the pancreatic tail. $\mathbf{b}$ Internal view of main pancreatic duct obtained by SpyGlass with altered vascularization and diminutive mucous membrane projections. cause the main duct measured $5 \mathrm{~mm}$, a direct view of the pancreatic tail was possible while biopsies were performed. Recent studies have shown SpyGlass to be a useful diagnostic and therapeutic tool in biliary diseases [3], but to the best of our knowledge, it is the first time it has been used in main duct IPMN with full pancreas examination to obtain direct visual images, perform biopsies, and safely change from a duodenopancreatectomy to a total pancreatectomy.

Endoscopy_UCTN_Code_CCL_1AF_2AZ_3AB

Competing interests

The authors declare that they have no conflict of interest.

The authors

José C. Ardengh ${ }^{1,2,3}$, Eloy Taglieri ${ }^{3}$, André $O$. Ardengh $^{4}$, Arthur F. De Almeida ${ }^{4}$, Rodrigo C. Surjan ${ }^{5}$, Fabio Makdissi ${ }^{5}$, Marcel A. Machado ${ }^{5}$

1 Universidad de São Paulo Faculdade de Medicina de Ribeirão Preto, Department of Surgery and Anatomy, São Paulo, Brazil

2 Universidad Federal de São Paulo, Diagnostic Imaging, São Paulo, Brazil
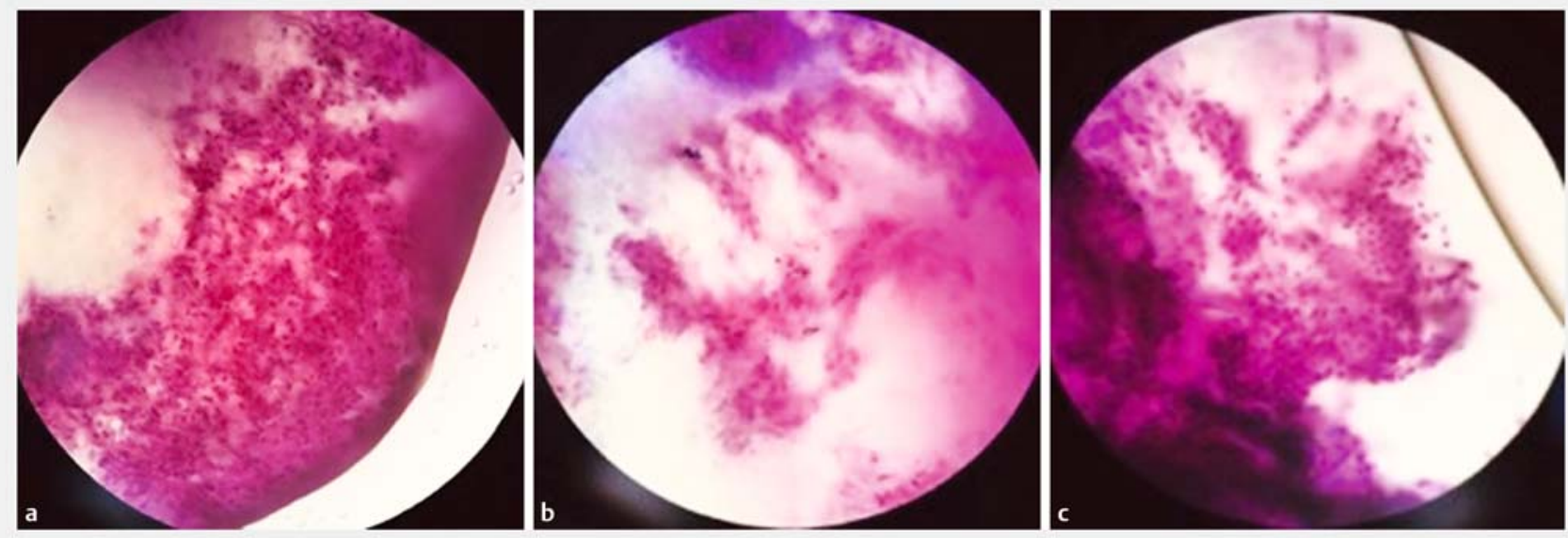

- Fig. 4 Hematoxylin and eosin stain images of fragments obtained with SpyGlass, seen as pancreatic head (a), body (b) and tail (c) Spybites. All revealed presence of high-grade dysplasia (HGD). 
3 Hospital 9 de Julho, Digestive Endoscopy Unit, São Paulo, Brazil

4 Faculdade de Ciências Médicas da Santa Casa de São Paulo, Department of Surgery, São Paulo, Brazil

5 Hospital 9 de Julho, Surgery Unit, São Paulo, Brazil

Corresponding author

José C. Ardengh, MD

Department of Surgery and Anatomy, Universidad de São Paulo Faculdade de Medicina de Ribeirão Preto, Alameda dos Arapanés, 881 - cj 111 São Paulo, São Paulo 04524-001, Brazil

Fax: +55-11-50558942

jcelso@uol.com.br
[1] Tanaka M, Fernandez-Del Castillo C, Kamisawa $T$ et al. Revisions of international consensus Fukuoka guidelines for the management of IPMN of the pancreas. Pancreatology 2017; 17: 738-753

[2] Ohtsuka T, Gotoh Y, Nakashima Y et al. Role of SpyGlass-DS in the preoperative assessment of pancreatic intraductal papillary mucinous neoplasm involving the main pancreatic duct. Pancreatology 2018; 18 : 566-571. doi:10.1016/j.pan.2018.04.012

[3] Laleman W, Verraes K, Van Steenbergen W et al. Usefulness of the single-operator cholangioscopy system SpyGlass in biliary disease: a single-center prospective cohort study and aggregated review. Surg Endosc 2017; 31: 2223-2232
Bibliography

Endoscopy 2021; 53: E191-E193

DOI 10.1055/a-1234-6094

ISSN 0013-726X

published online 2.9.2020

(c) 2020. Thieme. All rights reserved.

Georg Thieme Verlag KG, Rüdigerstraße 14,

70469 Stuttgart, Germany

\section{ENDOSCOPY E-VIDEOS}

https://eref.thieme.de/e-videos

回回 Endoscopy E-Videos is a free access online section, reporting 回左: on interesting cases and new techniques in gastroenterological endoscopy. All papers include a high quality video and all contributions are freely accessible online.

This section has its own submission website at

https://mc.manuscriptcentral.com/e-videos 